\title{
Hydroxychloroquine for the Treatment of Coronavirus Disease 2019: Evidence, Possible Mode of Action and Industrial Supply
}

\author{
Mario Pagliaro ${ }^{\star, a}$ and Francesco Meneguzzo $0^{\star, b}$ \\ ${ }^{a}$ Istituto per lo Studio dei Materiali Nanostrutturati, CNR, via U. La Malfa 153, 90146 Palermo, Italy \\ ${ }^{b}$ Istituto per la Bioeconomia, CNR, via Madonna del Piano 10, 50019 Sesto Fiorentino FI, Italy
}

Email: mario.pagliaro@cnr.it (M. P.), francesco.menguzzo@cnr.it (F. M.)

\begin{abstract}
Hydroxychloroquine, a known antiviral metabolite of chloroquine, is increasingly used along with antibiotic azithromycin for the treatment of COVID-19 infection. In about one month, India, the world's largest manufacturer, delivered the pharmaceutical ingredient for treating COVID-19 to over 50 countries. Coupled to azithromycin, the therapy is being used across the world both for patients staying at home at the early phase of symptoms, as well as for patients hospitalized. We summarize achievements as of late April 2020, review possible modes of action and suggest avenues for the quick scale-up of production of hydroxychloroquine.
\end{abstract}

Keywords hydroxychloroquine, coronavirus disease 2019, immunomodulator, cytokine storm, flow chemistry

\section{Introduction}

On March 20, 2020, Raoult and co-workers reported the outcomes of treating 26 patients (on average 51.2 years old) affected by the coronavirus disease 2019 (COVID-19) syndrome with the hydroxychloroquine sulfate alone and in combination with azithromycin. ${ }^{[1]}$ After 6 days, all patients treated with hydroxychloroquine (HCQ) and azithromycin combination were virologically cured. The team extended the new therapy to a much larger cohort of patients and on April 10, 2020 published online on the website of the Research Unit in Infectious and Tropical Emergent Diseases in Marseille the outcomes of the new protocol applied to 1,061 patients on average 43.6 years old $(46.4 \%$ male $) .{ }^{[2]}$ The scholars observed no cardiac toxicity and virological cure was obtained for 1,019 patients at day $15(96 \%)$, with $973(91.7 \%)$ cured within 10 days. ${ }^{[2]}$

South Korean doctors were reported to recommend the use of $\mathrm{HCQ}$ in combination with antivirals as early as of March 12, $2020 .{ }^{[3]}$ Even earlier, Bahrain was amid to be the first country in the world to administer the drug on February 26, 2020 following the registration of its first case on February $24^{\text {th }}$. One month later, the country recorded 225 COVID-19 patients, 4 deaths, and had already 190 patients cured and discharged from hospitals. ${ }^{[4]}$

On March 23, 2020, a physician (Vladimir Zelenko) in Monroe, New York state, published online similar excellent outcomes on treating his patients with shortness of breath and any patient in the high-risk category with $\mathrm{HCQ}$, azithromycin and zinc sulfate for five days in order to prevent hospitalization. ${ }^{[5]}$

Doctors in several other countries readily started to treat COVID-19 patients with this aminoquinoline used since decades across the world for the treatment of rheumatoid arthritis, lupus erythematosus and other autoimmune, inflammatory and dermatologic conditions. ${ }^{[6]}$

Italy, the country with the world's highest mortality rate chiefly due to deaths in one region (Lombardy), approved the use of $\mathrm{HCQ}$, chloroquine and several antivirals for the treatment of the disease by mid-March $2020 .^{[7]}$ Italy's doctors started to administer the drug to patients under home isolation and hospitalized. News of success was reported shortly afterwards, starting from Sicily where doctors in Catania were reported to observe rapid improvements in both the clinical and virological profiles of several patients as early as of March 27, 2020. ${ }^{[8]}$

The 1949 patent $^{[9]}$ disclosing the preparation of racemic hydroxychloroquine, namely 2-[[4-[(7-chloro-4-quinolinyl)amino]pentyl]ethylamino]ethanol, expired long ago. Hence, likewise to what happens for several other "generics" (a jargon term to indicate active pharmaceutical ingredients no longer under exclusivity manufacturing rights after the expiry of patent), its manufacturing chiefly occurs in India and in Southeast Asia, with Taiwan hosting the world's second largest plant.

Hence, when the COVID-19 infection became widespread in many countries, several governments asked India's government the urgent supply of the drug. India's government first on March 25, 2020 issued a ban the export of the drug,$^{[10]}$ and then lifted the ban starting to supply by mid-April a first list of 13 countries including the United States of America, Spain, Germany, Bahrain, Brazil, Nepal, Bhutan, Sri Lanka, Afghanistan, Maldives, Bangladesh, Seychelles, and Dominican Republic. ${ }^{[11]}$

On April 17, 2020, doctors from a health care provider focused on mostly elderly and chronic patients in Brazil confirmed Raoul's and Zelenko's findings reporting that out of 636 symptomatic outpatients of the 224 who refused treatment (control group), 12 were hospitalized (5.4\%), and of these 12 hospitalized, 5 patients died $(41 \%) .{ }^{[12]}$ On the other hand, of the 412 outpatients treated with HCQ and azithromycin, only 8 were hospitalized (1.94\%), and no death was observed.

In case of early treatment ( $<7$ days of symptoms), only $1.17 \%$ of treated patients needed hospitalization, while the percentage was raised to $3.2 \%$ for late treatment ( $>7$ days of symptoms). These outcomes were even more remarkable considering that patients in the treatment groups had higher prevalence of comorbidities including diabetes, immunosuppression state and stroke. ${ }^{[12]}$

The mechanism of action of HCQ against coronavirus is not yet known, even though the antiviral activity of chloroquine against flaviviruses, retroviruses, and the first SARS coronavirus (SARS-CoV) was reported in the early 2000s. ${ }^{[13]}$ 
In the following, we summarize achievements in the use of hydroxychloroquine as an antiviral against COVID-19 as of late April 2020. We review hypotheses concerning the possible modes of action, and suggest avenues for the quick scale-up of production of this valued pharmaceutical substance.

\section{Achievements in the Treatment of COVID-19}

In a 2003 review on the use of chloroquine to treat viral infections, Italy's scholars raised "the question of whether this old drug may experience a revival in the clinical management of viral diseases such as...severe acute respiratory syndrome" ${ }^{[13]}$

Indeed, the powerful in vitro inhibitory activity of chloroquine against the first severe acute respiratory syndrome coronavirus (SARS-CoV) infection and spread activity was reported in $2005,{ }^{[14]}$ namely less than three years after the outbreak of SARS in China's Guangdong province.

Similar evidence of in vitro action of chloroquine against the second severe acute respiratory syndrome coronavirus (SARS-CoV-2) was reported by Chinese scholars in early February 2020. ${ }^{[15]}$ Less than a month later, Raoult and co-workers reported synergistic effect in vitro of hydroxychloroquine sulfate combined with azithromycin (Figure 1). ${ }^{[16]}$

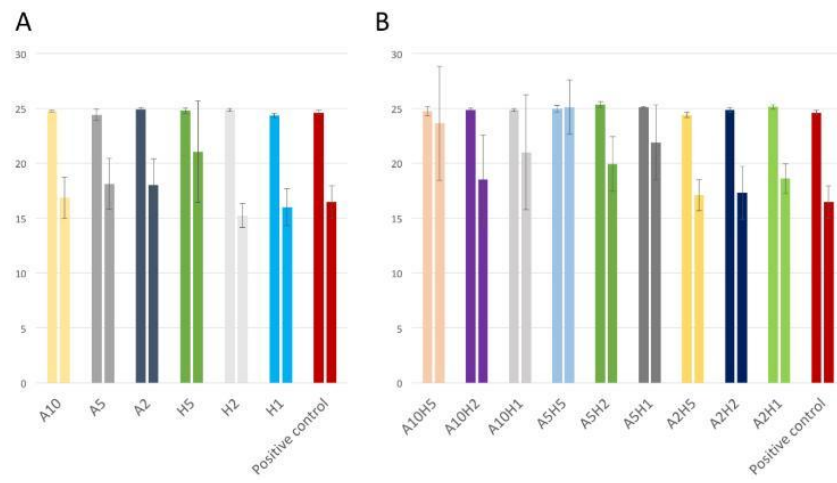

Figure 1 RNA viral quantification between 0 and 60 hours post infection for azithromycin (A) and hydroxychloroquine sulfate $(H)$ tested alone $(\mathbf{A})$ or in combination $(\mathbf{B})$ at different micromolar concentration specified by numbers $(\mathrm{A} 10=$ azithromycin $10 \mu \mathrm{M}$, and so on). Reproduced from Ref. [16], with kind permission.

Remarkably, the synergy between azithromycin and hydroxychloroquine was observed at concentrations achieved in vivo and detected in pulmonary tissues. In closer detail, while the team observed only a moderate effect on viral production for $\mathrm{HCQ}$ at $5 \mu \mathrm{M}$ (Figure 2A) compared to the positive control, for the combination of azithromycin and $\mathrm{HCQ}$, they observed inhibition of viral replication for wells containing $\mathrm{HCQ}$ at $5 \mu \mathrm{M}$ in combination with azithromycin at 10 and $5 \mu \mathrm{M}$ (Figure 1B).

Learning about the effective action of the combined therapy, using blood analysis data obtained between March 13 and March 23, 2020 from another set of 13 COVID-19 patients on average 68 years old hospitalized in intensive care unit, scholars in France recommended a dosage of $800 \mathrm{mg}$ of $\mathrm{HCQ}$ once daily on the first day so as to more rapidly reach therapeutic levels in patients that otherwise, using the $200 \mathrm{mg}$ three times daily dosing regimen would fail to reach the therapeutic blood level of $1-2 \mathrm{mg} / \mathrm{L} \cdot{ }^{[17]}$ Simulations used in the same prospective study to evaluate the pharmacokinetic properties of HCQ in the aforementioned patients, led the team to suggest that the $\mathrm{HCQ}$ dosing regimen should be optimized on the basis of pharmacokinetic data available in special populations.

Interestingly, the latter regimen is similar to that used by
Brazilian doctors which led to the marked reduction in the need for hospitalization when treating 412 symptomatic outpatients with $\mathrm{HCQ}$ and azithromycin, namely $\mathrm{HCQ} 800 \mathrm{mg}$ day 1 , followed by $400 \mathrm{mg} /$ day for 6 days, plus azithromycin 500 $\mathrm{mg} /$ day for $5 \mathrm{d.}{ }^{[12]}$

A first international survey of 6,227 physicians in 30 countries launched on March 25, 2020 and fielded over three days (25-27 March) found that $37 \%$ of those treating COVID-19 patients rated hydroxychloroquine as the "most effective therapy" from a list of 15 options. ${ }^{[18]}$ The third survey of 4016 COVID-19 treaters fielded over April 6-9, 2020 $0^{[19]}$ found globally a $17 \%$ increase in the share of physicians who have used $\mathrm{HCQ}$ (from $33 \%$ to $50 \%$ ) and azithromycin (from $41 \%$ to $58 \%$ ) with the top three treatments prescribed being azithromycin (58\%), hydroxychloroquine $(50 \%)$, and bronchodilators (48\%). ${ }^{[19]}$ Overall, HCQ rated second most effective treatment after plasma and doctors in France (59\%), Italy $(52 \%)$, Spain $(50 \%)$ and China $(49 \%)$ had higher perception of hydroxychloroquine efficacy. ${ }^{[19]}$

\section{Possible Modes of Action}

On late March 2020, chemistry scholars in Unites States published the outcomes of molecular quantum mechanical modeling of the interaction of hydroxychloroquine and azithromycin to the SARS-CoV-2 Spike (S)protein-ACE2 complex (Figure 2). ${ }^{[20]}$

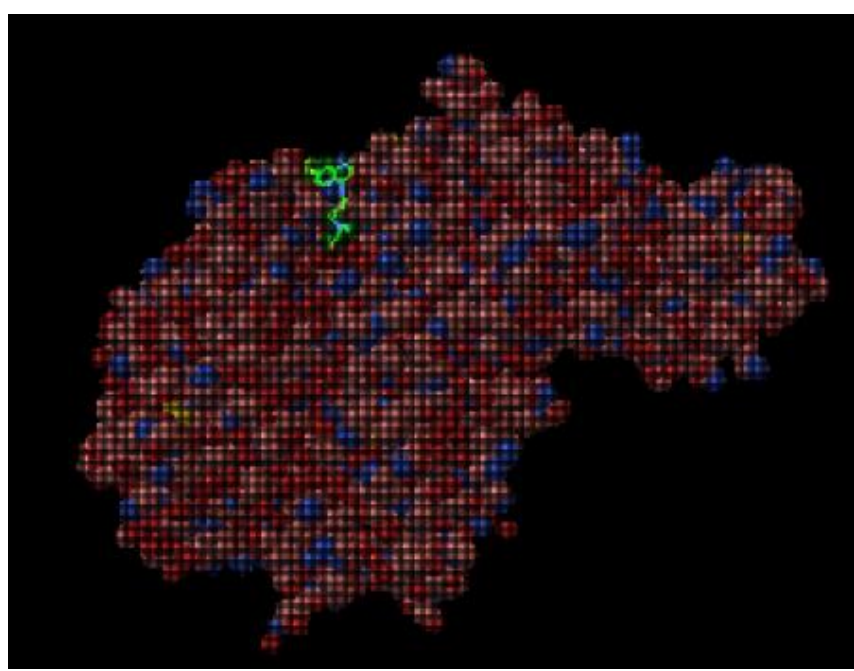

Figure 2 Binding conformation of hydroxychloroquine that touches the interaction points between the Spike and ACE2. Reproduced from Ref. [20], under CC BY 4.0 License.

Present in endothelial cells, arterial smooth muscle cells, and most abundant in humans epithelia of the lung and small intestine, human cell receptor angiotensin converting enzyme II (ACE2) is the critical receptor for SARS-CoV ${ }^{[21]}$ and also for SARS-CoV-2 $2^{[22]}$ viruses so that, in principle, inhibiting this interaction with a suitable drug or cocktail of drugs will prevent and cure the COVID-19 infection.

According to said modeling, HCQ does not bind to ACE2 but increases its acidity in the interaction between the ACE2 and SARS-CoV-2 spike thus inducing degradation of the spike and lowering the virus ability to spread further, whereas azithromycin directly targets the binding interaction site between the SARS-CoV-2 spike and ACE2 thanks to high binding affinity. ${ }^{[20]}$

Since the early 2000 s several studies, recently summarized by Chinese scholars, ${ }^{[23]}$ have been addressed to investigate the origins of the antiviral action of chloroquine and HCQ. 
Hydroxychloroquine is the first metabolite of chloroquine. Besides the role of both aminoquinolines as bases raising the $\mathrm{pH}$ within endosomes and lysosomes and interfering with viral infection, a key role of $\mathrm{HCQ}$ is in the inhibition of the production of three key proinflammatory cytokines (tumor necrosis factor alpha, interleukin 1, and interleukin 6) produced by the immune system from mononuclear phagocytes in response to the viral infection. ${ }^{[24,23,13]}$

The latter cytokines have a primary role in the pathogenesis of several inflammatory diseases including rheumatoid arthritis.

A vast number of highly oxidant free radicals are released by immune cells in reaction to these and other proinflammatory cytokines causing acute respiratory distress syndrome and failure of multiple organs, ${ }^{[25]}$ which requires the employment of immunosuppressants to prevent and attenuate cytokine storms.

Preventing cytokine formation, HCQ prevents the possibility of a cytokine storm, which have been implicated in many fatal outcomes of both SARS and COVID-19 infectious diseases. ${ }^{[26]}$ Remarkably, also another immunosupressant such as anti-IL6 monoclonal antibody tocilizumab has been used both to treat cytokine storm ${ }^{[27]}$ and severe COVID-19 patients. ${ }^{[28]}$

\section{Industrial Supply of Hydroxycloroquine}

Classified as an essential medication for a basic healthcare system, hydroxycloroquine is still synthesized according to the same route developed in 1950 by Surrey and Hammer (Figure 3). ${ }^{[29]}$

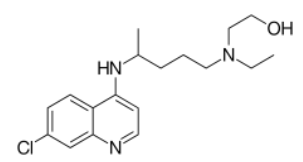

Figure 3 Molecular structure of hydroxychloroquine.

The patent on the compound and the method of preparation of $\mathrm{HCQ}$ as hydroxychloroquine diphosphate by reacting 4,7-dichloroquinoline with $N$-ethyl- $N$ - $\beta$-hydroxyethyl-I,4-pentadiamine in the presence of potassium iodide and phenol at a temperature of $125-130{ }^{\circ} \mathrm{C}$ for $>18 \mathrm{~h}$ to eventually obtain crude hydroxychloroquine further isolated as diphosphate salt with an overall yield of $35 \%{ }^{[9]}$ has long expired.

However, a recent study on today's manufacturing of hydroxychloroquine sulfate, aimed to identify needs in case of urgent scale-up of its current production levels due to COVID-19, found that Surrey's route "is still practiced by a majority of API (active pharmaceutical ingredient) suppliers, variants of improvement notwithstanding". [30] Chiefly manufactured in India, and to a lesser extent in China and Europe at about 300 tonnes per year rate to treat about 3 million rheumatoid arthritis and lupus patients across the world, $\mathrm{HCQ}$ has been historically priced at less than $\$ 150 / \mathrm{kg}^{[30]}$

Its multi-step synthesis epitomizes manufacturing processes in the fine chemical industry supplying APIs to the pharmaceutical sector as it takes place in batch reactors starting from multiple reactants including 5-chloropentan-2-one and 4,7-dichloroquinoline purchased by other fine chemical suppliers. In general, the reactants used in HCQ synthesis are derived from oil and include substances available in virtually unlimited amounts such as benzene, ethylene, propylene, ammonia, chlorine and other commodity chemicals. ${ }^{[30]}$

Once synthesized and purified, HCQ is supplied to tens of pharmaceutical companies across the world, which commercialize their drugs containing $\mathrm{HCQ}$ as an active ingredient under over one hundred different brand names. ${ }^{[31]}$

An alternative and more efficient route (52\% yield increase on conventional process) mostly based on flow chemistry was reported by Gupton and co-workers in 2018. ${ }^{[32]}$

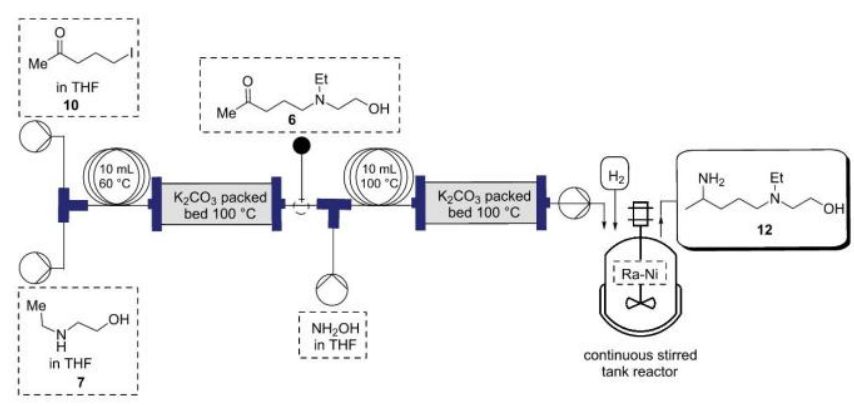

Figure 4 Semi-continuous synthesis of key intermediate HCQ precursor 5-(ethyl(2-hydroxyethyl)amino)-2-aminopentane through catalytic hydrogenation of the oxime obtained via a combination of packed bed flow reactors. Reproduced from Ref. [32], with kind permission.

Demonstrated by the team at a multigram-scale, the new semi-continuous process affords the key intermediate 5-(ethyl(2-hydroxyethyl)amino)-2-aminopentane (12) through catalytic hydrogenation of the oxime quickly obtained via a combination of packed bed flow reactors (Figure 4). The intermediate is then reacted in batch with 4,7-dichloroquinoline to afford HCQ with an isolated yield of $78 \%$.

Showing the industry's awareness of the obsolescence of the route developed in 1950, another new process for preparing hydroxychloroquine by reacting 4,7-dichloroquinoline with $N$-ethyl- $N$ - $\beta$-hydroxyethyl-1,4-pentadiamine under solvent-free and catalyst-free conditions by simply carrying out the process under $10-20$ pressure in a moisture-free $\mathrm{N}_{2}$ atmosphere was reported by industrial researchers in South Korea in 2010. ${ }^{[3]}$ The method inhibits the formation of byproducts, avoids the use of toxic phenol used as reaction solvent, and decreases production costs by decreasing the reaction temperature and reaction time

\section{Conclusions and Outlook}

Following the outbreak of COVID-19 infection due to Sars-CoV-2 virus, hydroxychloroquine combined with antibiotic azithromycin (and zinc sulfate in another experimental therapeutic approach) quickly emerged in several countries as one of the most effective treatments for patients.

Especially useful during the early phase of the syndrome preventing symptomatic patients from being hospitalized, biomedical scholars and physicians in several countries including France, ${ }^{[1]}$ Brazil, ${ }^{[12]}$ USA, ${ }^{[5]}$ Italy, ${ }^{[3]}$ South Korea, Bahrain $^{[4]}$ and Senegal ${ }^{[34]}$ reported that the treatment was successful.

Suddenly, several countries asked India's government the urgent supply of the drug. India's government first issued a ban the export of the drug, ${ }^{[10]}$ and then lifted the ban starting to supply the pharmaceutical substance to over 50 countries. ${ }^{[35]}$

Reports of hydroxycloroquine shortages, with people depleting stocks at pharmacies in several European, North and South American and African countries shortly followed, causing concern $^{[36]}$ for over 3 million patients of malaria, rheumatoid arthritis, lupus erythematosus and other autoimmune, inflammatory and dermatologic conditions regularly treated with $\mathrm{HCQ}$ across the world. ${ }^{[6]}$

Three main lessons emerge from findings summarized in this study reviewing early achievements in the use of HCQ for COVID-19 treatment, its possible modes of action and commercial supply.

First, quick action of pioneering medical teams from Bahrain to France to South Korea inspired by reasons of urgency is an exemplary case of situational leadership in 
clinical practice ${ }^{[37]}$ as well as in biomedical research quickly transferring the outcomes of laboratory research ${ }^{[16]}$ to experimental therapy. ${ }^{[1]}$ In other words, physicians from across the world did not wait for large randomized double blind placebo control studies, but quickly acted using well-known and long approved drugs such as hydroxychloroquine, azithromicyin and zinc sulfate in the attempt to save lives, thereby honoring their Hyppochratic oath.

Second, policy makers should evaluate the opportunity to establish Government-owned pharmaceutical production of essential medicines, most of which today are free from patent protection such as hydroxychloroquine and azithromicyin, based on state of the art industrial flow chemistry techniques which uniquely enable to scale-up production levels without the need to scale-up production facilities. ${ }^{[38]}$

Indeed, regardless of HCQ being listed amid the essential medicines for the treatment of rheumatoid disorders in the WHO Model List of Essential Medicines, ${ }^{[39]}$ several countries with no domestic production of the drug asked India, the world's leading production country, to urgently supply the drug. This forced India's government first to ban the export of the drug ${ }^{[10]}$ and then to lift the ban to supply over 50 countries. ${ }^{[35]}$

Third, scholars of all disciplines should embrace the posting of preprints as a normal communication tool of their research activity. Also during the ongoing COVID-19 crisis, indeed, preprints largely emerged as a key resource to immediately share progress ${ }^{[1,5,12,16,18]}$ on experimental therapy as well as for potentially therapeutic molecules such as hesperidin. ${ }^{[40,41]}$

Highly accessed immediately after online publication on different servers such as research hospital websites and preprint servers, these studies are already widely cited showing once again to scholars of disciplines so far reluctant to embrace preprints such as chemists, ${ }^{[42]}$ that the transition to open science only provides benefits for all. ${ }^{[43]}$

\section{Acknowledgements}

M. P. thanks Professor B. Frank Gupton, Virginia Commonwealth University, for useful discussion concerning the semi-continuous synthesis of hydroxychloroquine. The image of SARS-CoV-2 virus by National Institute of Allergy and Infectious Diseases retrieved from creativecommons.org for the graphics illustrating this study is reproduced under CC BY license.

\section{Author Contributions}

Following are the details of the contributions made by each of the authors for the manuscript: M. P. and F. M. conceived the study. M. P. wrote the first version of the manuscript. F. M. revised the first version.

\section{Conflict of Interest}

The authors declare no conflict of interest.

Copyright () 2020 Mario Pagliaro and Francesco Meneguzzo. This article is an open access article distributed under the terms and conditions of the Creative Commons Attribution (CC BY) license (http://creativecommons.org/licenses/by/4.0/). The use, distribution or reproduction in other forums is permitted, provided the original author(s) or licensor are credited and that the original publication in this journal is cited, in accordance with accepted academic practice. No use, distribution or reproduction is permitted which does not comply with these terms.

\section{References}

[1] Gautret, P.; Lagier, J. C.; Parola, P.; Hoang, V. T.; Medded, L.;
Mailhe, M.; Doudier, B.; Courjon, J.; Giordanengo, V.; Vieira, V. E.; Dupont, H. T.; Honore, S.; Colson, P.; Chabriere, E.; La Scola, B.; Rolain, J. M.; Brouqui, P.; Raoult, D. Hydroxychloroquine and Azithromycin as a treatment of COVID-19: preliminary results of an open-label non-randomized clinical trial. medRxiv 2020, DOI: 10.1101/2020.03.16.20037135.

[2] See at the URL: www.mediterranee-infection.com/wp-content/ uploads/2020/04/Abstract_Raoult_EarlyTrtCovid19_09042020_vD 1v.pdf.

[3] Shim, E. South Korea experts recommend anti-HIV, anti-malaria drugs for COVID-19, UPI, 12 March 2020. See at the URL: www.upi.com/Top_News/World-News/2020/03/12/South-Korea-ex perts-recommend-anti-HIV-anti-malaria-drugs-for-COVID-19/6961 584012321.

[4] Khalid, T. Bahrain among first countries to use Hydroxychloroquine to treat coronavirus, Al Arabiya English, 26 March 2020. See at the URL: https://english.alarabiya.net/en/News/gulf/2020/03/26/Bahrain-one-of-the-first-countries-to-use-Hydroxychloroquine-to-treatcoronavirus.

[5] Zelenko, V. A Report on Successful Treatment of Coronavirus, March 23, 2020. See at the URL: http://archive.vn/2EbfJ.

[6] Schrezenmeier, E.; Dörner, T. Mechanisms of action of hydroxychloroquine and chloroquine: implications for rheumatology. Nat. Rev. Rheumatol. 2020, 16, 155-156.

[7] Agenzia italiana del farmaco, Determina 17 marzo 2020, Rimborsabilita' a carico del Servizio sanitario nazionale dei medicinali clorochina, idrossiclorochina, lopinavir/ritonavir, danuravir/cobicistat, darunavir, ritonavir per il trattamento anche in regime domiciliare dei pazienti affetti da infezione da SARS-CoV2 (COVID-19), Gazzetta Ufficiale Serie Generale n.69 del 17-03-2020.

[8] Cacopardo, B. S. In: D. De Luca, Farmaco contro la malaria per combattere il Covid-19? L'infettivologo Cacopardo: «l primi risultat sono buoni», Meridionews, 27 March, 2020. See at the URL https://catania.meridionews.it/articolo/86513/il-farmaco-contro-lamalaria-per-curare-il-coronavirus-linfettivologo-cacopardo-i-primi-ri sultati-sono-buoni/.

[9] Surrey, A. R. 7-chloro-4-[5-(n-ethyl-n-2-hydroxyethylamino)-2-pentyl] aminoquinoline, its acid addition salts, and method of preparation. US2546658A, 1950.

[10] Government of India, Ministry of Commerce \& Industry, Notification No.54/2015-2020, New Delhi, 25 March, 2020. See at the URL: https://dgft.gov.in/sites/default/files/notification\%2054_0.pdf.

[11] Bangladesh Among 13 Nations To Get Anti-Malarial Drug From India, ndtv.com, April 12, 2020. See at the URL: www.ndtv.com/ india-news/coronavirus-us-spain-germany-in-indias-list-of-13-coun tries-to-export-hydroxychloroquine-2210477.

[12] Esper, R. B.; da Silva, R. S.; Oikawa, F. T. C.; Castro, M. M.; Razuk-Filho, A.; Junior, P. B. B.; Lotze, S. W.; da Rocha, C. N.; de Sá Cunha Filho, R.; de Oliveira, S. E. B.; Ribeiro, P. L.; Martins, V. C. V.; Bueno, F. S. B.; Esper, P. L. G.; Parrillo, E. F. Empirical treatment with hydroxychloroquine and azithromycin for suspected cases of COVID-19 followed-up by telemedicine, Dropbox, 2020. See at the URL: www.dropbox.com/s/5qm58cd4fneeci2/2020.04.15\%20journal\%20manuscript\%20final.pdf?dl=0.

[13] Savarino, A.; Boelaert, J. R.; Cassone, A.; Majori, G.; Cauda, R. Effects of chloroquine on viral infections: an old drug against today's diseases? Lancet Infect. Dis. 2003, 3, 722-727.

[14] Vincent, M. J.; Bergeron, E.; Benjannet, S.; Erickson, B. R.; Rollin, P. E.; Ksiazek, T. G.; Seidah, N. G.; Nichol, S. T. Chloroquine is a potent inhibitor of SARS coronavirus infection and spread. Virol. J. 2005, 2, 69.

[15] Wang, M.; Cao, R.; Zhang, L.; Yang, X.; Liu, J.; Xu, M.; Shi, Z.; Hu, Z.; Zhong, W.; Xiao, G. Remdesivir and chloroquine effectively inhibit the recently emerged novel coronavirus (2019-nCoV) in vitro. Cell. Res. 2020, 30, 269-271. 
[16] Andreani, J.; Le Bideau, M.; Duflot, I.; Jardot, P.; Rolland, C.; Boxberger, M.; Bou Khalil, J. Y.; Baudouin, J.-P.; Rolain, J.-M.; Colson, P.; La Scola, B.; Raoult, D. In vitro testing of Hydroxychloroquine and Azithromycin on SARS-CoV-2 shows synergistic effect, mediterranee-infection.com 2020. See at the URL: www.mediterranee-infection.com/wp-content/uploads/2020/ 03/La-Scola-et-al-V1.pdf.

[17] Perinel, S.; Launay, M.; Botelho-Nevers, É.; Diconne, É.; Louf-Durier, A.; Lachand, R.; Murgier, M.; Page, D.; Vermesch, R.; Thierry, G.; Delavenne, X. Towards Optimization of Hydroxychloroquine Dosing in Intensive Care Unit COVID-19 Patients. Clin. Infect. Dis. 2020, ciaa394.

[18] Sermo, Sermo's COVID-19 Real Time Barometer Study WAVE I: March 25-27, sermo.com, 2020. See at the URL: https://public-cdn.sermo.com/covid19/c8/be4e/4edbd4/dbd4ba4ac 5a3b3d9a479f99cc5/wave-i-sermo-covid-19-global-analysis-final.p df.

[19] Sermo, Sermo's COVID-19 Real Time Barometer Study WAVE III: April 7-9, sermo.com, 2020. See at the URL: https://public-cdn.sermo.com/covid19/dd/c7f7/f7344a/344a00427889ec27e2b8df1c1 5/w3-sermo-covid-19-barometer.pdf.

[20] Sandeep, S.; McGregor, K. Energetics Based Modeling of Hydroxychloroquine and Azithromycin Binding to the SARS-CoV-2 Spike (S)Protein-ACE2 Complex. ChemRxiv 2020, DOI: 10.26434/ chemrxiv.12015792.

[21] Kuba, K.; Imai, Y.; Rao, S.; Gao, H.; Guo, F.; Guan, B.; Huan, Y.; Yang, P.; Zhang, Y.; Deng, W.; Bao, L.; Zhang, B.; Liu, G.; Wang, Z.; Chappell, M.; Liu, Y.; Zheng, D.; Leibbrandt, A.; Wada, T.; Slutsky, A. S.; Liu, D.; Qin, C.; Jiang, C.; Penninger, J. M. A crucial role of angiotensin converting enzyme 2 (ACE2) in SARS coronavirusinduced lung injury. Nat. Med. 2005, 11, 875-879.

[22] Monteil, V.; Kwon, H.; Prado, P.; Hagelkrüys, A.; Wimmer, R. A.; Stahl, M.; Leopoldi, A.; Garreta, E.; del Pozo, C. H.; Prosper, F.; Romero, J. P.; Wirnsberger, G.; Zhang, H.; Slutsky, A. S.; Conder, R.; Montserrat, N.; Mirazimi, A.; Penninger, J. M. Inhibition of SARS-CoV-2 infections in engineered human tissues using clinical-grade soluble human ACE2. Cell 2020, 181, 905.

[23] Zhou, D.; Dai, S.-M.; Tong, Q. COVID-19: a recommendation to examine the effect of hydroxychloroquine in preventing infection and progression. J. Antimicrob. Chemoth. 2020, 75, 1667-1670.

[24] Jang, C.-H.; Choi, J.-H.; Byun, M.-S.; Jue, D.-M. Chloroquine inhibits production of TNF- $\alpha, \quad \mathrm{IL}-1 \beta$ and IL- 6 from lipopolysaccharide-stimulated human monocytes/macrophages by different modes. Rheumatology 2006, 45, 703-710.

[25] Tisoncik, J. R.; Korth, M. J.; Simmons, C. P.; Farrar, J.; Martin, T. R. Katze, M. G. Into the eye of the cytokine storm. Microbiol. Mol. Biol. Rev. 2012, 76, 16-32

[26] Ye, Q.; Wang, B.; Mao, J. The pathogenesis and treatment of the 'Cytokine Storm' in COVID-19. J. Infect. 2020, 80, 607-613.

[27] Behrens, E. M.; Koretzky, G. A. Cytokine Storm Syndrome: Looking Toward the Precision Medicine Era. Arthritis Rheumatol. 2017, 69, 1135-1143.

[28] Xu, X. L.; Han, M. F.; Li, T. T.; Sun, W.; Wang, D. S.; Fu, B. Q.; Zhou, Y. G.; Zheng, X. H.; Yang, Y.; Li, X. Y.; Zhang, X. H.; Pan, A. J.; Wei, H. M. Effective Treatment of Severe COVID-19 Patients with Tocilizumab. Proc. Natl. Acad. Sci. U. S. A. 2020, 117, 10970-10975.

[29] Surrey, A. R.; Hammer, H. F. The Preparation of 7-Chloro-4-(4-(N- ethyl- $N$ - $\beta$-hydroxyethylamino)-1-methylbutylamino)-quinoline and Related Compounds. J. Am. Chem. Soc. 1950, 72, 1814.

[30] Zhang, T. Y.; Zhong, B. Meeting the Potential Emergency Global Drug Supply Challenge of Hydroxychloroquine for COVID-19. Med. Drug Discov. 2020, 5, 100036.

[31] An active pharmaceutical ingredients online database listed more than 100 hydroxychloroquine trade names as of late April 2020 See at the URL: https://drugs-about.com/ing/hydroxychloroquine.html.

[32] Yu, E.; Mangunuru, H. P. R.; Telang, N. S.; Kong, C. J.; Verghese, J.; Gilliland III, S. E.; Ahmad, S.; Dominey, R. N.; Gupton, B. F. High-yielding continuous-flow synthesis of antimalarial drug hydroxychloroquine. Beilstein J. Org. Chem. 2018, 14, 583-592.

[33] Min, Y. S.; Cho, H.-S.; Mo, K. W. New preparation of hydroxychloroquine. WO2010027150A2.

[34] Seyd, M. cit. In: C. Cuordifede, "Nous constatons une guérison plus rapide": Moussa Seydi, le médecin sénégalais qui s'est inspiré des travaux de Didier Raoult, Marianne, April 1, 2020. See at the URL: www.marianne.net/monde/nous-constatons-une-guerisonplus-rapide-moussa-seydi-le-medecin-senegalais-qui-s-est-inspire ?utm_medium=Social\&utm_source=Twitter\#Echobox=158714639 7.

[35] Laskar, R. H. Covid-19: India approves supply of hydroxychloroquine to 55 countries as commercial sales or grants, Hindustan Times, 16 April, 2020.

[36] Mehta, B.; Salmon, J.; Ibrahim, S. Potential Shortages of Hydroxychloroquine for Patients with Lupus During the Coronavirus Disease 2019 Pandemic. JAMA Health Forum 2020, 1, e200438.

[37] van der Wal, M. A.; Scheele, F.; Schönrock-Adema, J.; Jaarsma, A. D. C.; Cohen-Schotanus, J. Leadership in the clinical workplace: what residents report to observe and supervisors report to display: an exploratory questionnaire study. BMC Med. Educ. 2015, 15 195.

[38] de Souza, R. O. M. A.; Watts, P. Flow processing as a tool for API production in developing economies. J. Flow Chem. 2017, 7 , $146-150$.

[39] World Health Organization, Model List of Essential Medicines, 18th list, Geneva: 2013. See at the URL: www.who.int/medicines/publications/essentialmedicines/18th_EML.pdf.

[40] Utomo, R. Y.; Ikawati, M.; Meiyanto, E. Revealing the Potency of Citrus and Galangal Constituents to Halt SARS-CoV-2 Infection. Preprints 2020, 2020030214 (DOI: 10.20944/preprints202003.0214.v1).

[41] Meneguzzo, F.; Ciriminna, R.; Zabini, F.; Pagliaro, M. Review of Evidence Available on Hesperidin-Rich Products as Potential Tools against COVID-19 and Hydrodynamic Cavitation-Based Extraction as a Method of Increasing Their Production. Processes 2020, 8, 549 .

[42] Demma Carà, P.; Ciriminna, R.; Pagliaro, M. Has the time come for preprints in chemistry? ACS Omega 2017, 2, 7923-7928.

[43] Pagliaro, M. Scientific Publishing Today: Education as the Key Enabler for the Transition to Open Science. Preprints 2019, 2019100057 (DOI: 10.20944/preprints201910.0057.v4).

Received June 30, 2020 Accepted July 7, 2020 